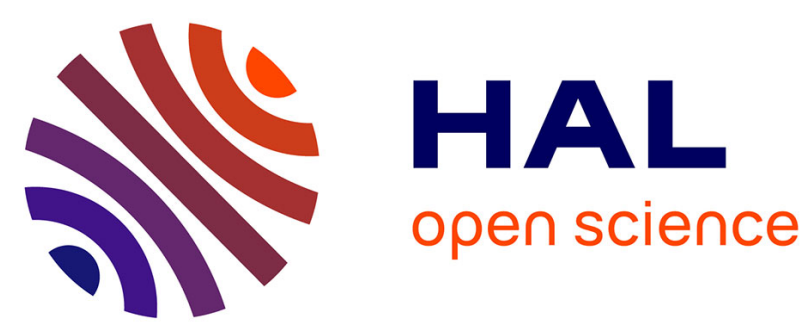

\title{
Protandry and postandry in two related butterflies: conflicting evidence about sex-specific trade-offs between adult size and emergence time
}

Gabriel Nève, Michael F. Singer

\section{- To cite this version:}

Gabriel Nève, Michael F. Singer. Protandry and postandry in two related butterflies: conflicting evidence about sex-specific trade-offs between adult size and emergence time. Evolutionary Ecology, 2008, 22 (6), pp.701-709. 10.1007/s10682-007-9192-6 . hal-01957277

\section{HAL Id: hal-01957277 \\ https://hal-amu.archives-ouvertes.fr/hal-01957277}

Submitted on 17 Dec 2018

HAL is a multi-disciplinary open access archive for the deposit and dissemination of scientific research documents, whether they are published or not. The documents may come from teaching and research institutions in France or abroad, or from public or private research centers.
L'archive ouverte pluridisciplinaire HAL, est destinée au dépôt et à la diffusion de documents scientifiques de niveau recherche, publiés ou non, émanant des établissements d'enseignement et de recherche français ou étrangers, des laboratoires publics ou privés. 
As published in

Evolutionary Ecology (2008) 22:701-709

DOI 10.1007/s10682-007-9192-6

\title{
The original publication is available at www.springerlink.com
}

\section{Protandry and postandry in two related butterflies: conflicting evidence about sex-specific trade-offs between adult size and emergence time}

\author{
Gabriel Nève ${ }^{1}$ and Michael C. Singer ${ }^{2}$ \\ 1. EA 3781 Evolution Génome Environnement, Case 36, Université de Provence, 3 place \\ Victor Hugo, 13331 Marseille Cedex 3, France. Email : neve@up.univ-mrs.fr \\ now at : Aix Marseille Univ, Univ Avignon, CNRS, IRD, IMBE, Case 421, 13397 \\ Marseille cedex 20, France. \\ Email : gabriel.neve@imbe.fr \\ [corresponding author] \\ 2. Integrative Biology, Patterson Laboratories, University of Texas, Austin, Texas 78712, \\ U.S.A. Email : sing@mail.utexas.edu \\ Running title : Protandry and postandry in Euphydryas butterflies \\ Keywords : Protandry, postandry, size, Euphydryas aurinia, Euphydryas editha,
}

Abstract

Natural selection acting on timing of metamorphosis can be sex-specific, resulting in differences in timing between males and females. Insects with discrete generations frequently show protandry: males usually mature before females. Both Euphydryas editha and $E$. aurinia butterflies followed this trend. The present study was motivated by the unusual observation of consistent postandry in addition to protandry. In a single E. editha population observed over 20 years the emergence period of males was longer than that of females, both the first and last emerging individuals being males. Variance of timing among individual $E$. editha larvae is imposed by spatial patchiness of the snowmelt that releases them from winter diapause. If individual larvae released late from diapause were to compensate for their lateness by shortening their development times, they would be small at maturity. If such compensation were only partial, they would be both late and small. Size and timing would become associated. If females were more prone to such partial compensation than males, the observations of postandry could be explained and the prediction made that any tendency for late individuals to be small should be stronger in females than in males. This was the case: in one year late males were the same size as early males, in a second year they were larger. Late females were significantly smaller than early females in both years. In E. aurinia, results were opposite both to theoretical prediction and to the observations from $E$. editha: although the male emergence period was longer than

Nève \& Singer. Protandry and postandry in Euphydryas butterflies, Evol. Ecol (2008) 22:701-709, page 1 
that of females exactly as in E. editha, late males were smaller than early ones, while late females were not small. The data from $E$. editha support the hypothesis of a sex-specific trade-off between size and emergence time, the data from E. aurinia do not.

\section{Introduction}

In animals which metamorphose, a juvenile that has reached a size where transition to the adult stage is possible=can choose between commencing metamorphosis or delaying it and gathering further resources as a larva. When larvae are more susceptible than adults to predation, such delay incurs a cost in terms of prolonged larval exposure to predators (Benard 2004 ; Vonesh \& Warkentin 2006; Stearns, 1992). In such cases individuals programmed to delay metamorphosis suffer greater exposure to predators as larvae but, if they survive, have increased body size, conferring higher fecundity to females and competitive advantage to males (Berger et al. 2006). The opposing selective forces associated with predation and reproduction then result in a trade-off between maximizing size, hence fecundity (e.g. Taylor et al. 1998), and minimizing predation (Forrest, 1987; Candolin and Voigt, 2003).

In most temperate-zone butterfly species emergence is protandrous (males emerge before females) and males are smaller than females (Wiklund and Forsberg 1991), through shorter male larval developmental and pupal times (Fischer and Fiedler, 2001a). Selection for protandry arises because males that emerge before peak female emergence encounter more virgin females than later males (Iwasa et al. 1983). In a north temperate butterfly community (Minnesota), species with discrete generations tended to be more sexually dimorphic (females larger than males) than species with overlapping generations or than those which refrained from mating till after an adult diapause (Singer 1982). This difference between species with discrete and overlapping generations implies some influence of sexual selection for protandry on size dimorphism. These bodies of evidence suggest that in univoltine butterfly species the selection pressures on size and phenology are sexdependent (Wiklund and Forsberg 1991).

Size and phenology may differ between the sexes even in a constant environment if each sex were programmed to grow for a particular length of time to a particular size, with males normally being the smaller and earlier sex. However, in the presence of environmental variation, sex-specific plastic responses could complement and alter this relationship. Here we use field data from two congeneric butterflies species (genus Euphydryas), to test ideas about how such sex-specific responses might interact with the trade-offs between size and emergence time that have been predicted (Singer 1982, Zonneveld 1996). 


\section{Materials and methods}

Our study populations of Euphydryas aurinia and E. editha are univoltine (Lepidoptera, Nymphalidae) which diapause as partly-grown larvae. In spring, larvae resume feeding, and produce a single, discrete generation of adults which fly for about a month between May and July, with precise timing of depending on the local weather conditions. Most individuals tend to stay in their natal habitat patch, but occasional movements between patches occur.

Euphydryas editha (Boisduval)

\section{Size}

At Rabbit Meadow, Tulare County, California, E. editha individuals were captured and measured at the beginning and at the end of the period of adult emergence. This was done in both 1995 and 1996. Each individual was measured, marked and released to prevent measuring the same insect twice. Altogether, 139 and 215 individuals were measured in 1995 and 1996 respectively. Comparisons of wing lengths of early-emerging and lateemerging insects were performed using standard $t$-tests.

Phenology

We noted the sex of the last freshly-emerged individual $E$. editha (with no visible scale loss) seen at Rabbit Meadow in each year from 1983 and to 2006, omitting the years 1984, 1987, 1990 and 2003. In each year observations were made daily. Because of the possibility that the fresh males observed at the end of the emergence season were immigrants, in one year (1986) ten small (5 m square) patches were searched intensively to record the sex of the last teneral insect (that could not yet fly). This was done in a year of extremely high insect density (Thomas et al. 1996), in which an average of around 20 teneral insects in each $5 \mathrm{~m}$ square patch were found.

\section{Euphydryas aurinia (Rottemburg)}

Our study site was at Deiffelt, Luxembourg province, Belgium. A Mark-Release-Recapture survey of E. aurinia was performed daily from 27 May to 4 July 1995, except on rainy days. On each of the 23 sunny days, the whole site was visited and a $20 \mathrm{~m}$ grid was systematically searched. Each captured individual was individually marked with a number on the underside of the left hindwing. Upon capture, the length of the forewing was measured and the wear of the wings was assessed on a 4 point scale, from fresh to very worn. All individuals were released at the site of capture immediately after marking. A total of 209 males and 118 females were captured, of which 152 and 86 respectively had been first captured when fresh or undamaged (wing wear classes 1 and 2).

As most males emerge before females do, a model incorporating both sex and capture date as possible explanatory variables would have violated the assumption of independence between variables. The data for each sex were thus analyzed separately. Correlations between two variables (size and day), for each sex, were computed using Spearman's $\rho$ rank correlation coefficient. Log transformations did not normalize the data. All statistical analyses were done using $\mathrm{R}(\mathrm{R}$ 
Development Core Team, 2004), except daily population size and births which were estimated using Jolly-Seber model with the POPAN5 program (Arnason et al., 1998; Arnason and Schwarz, 1999). As the site was isolated from other populations of the species, all new individuals caught on the site had emerged locally. The mean day of emergence was calculated using the mean of all individual birth dates.

\section{Results}

\section{Euphydryas editha}

Wing size distribution did not differ significantly from Normal distribution for each time/sex combination (Shapiro-Wilk test, smallest $P=0.16$ ). In both years, females were significantly smaller at the end of the emergence season, whereas there was a trend the other way, males being bigger at the end of the season than at the beginning, in 1995, and there was no trend for males in 1996 (Table 1).

There was a strong and significant tendency for first and last insects to emerge to be males. The last freshly-emerged insect was male in 18 of the 20 years and female in one year. In the remaining year the last two freshly-emerged insects were a male and a female, observed on the same day. The observed ratio of 18:2 is significant at $P=0.0004$. (two-sided binomial test, R Development Core Team, 2004). We missed the first few days of the emergence season in all but 9 years; in 8 of those 9 years the first insect observed was also a male; in the last year of observation, 2006, the first E. editha seen was female. The ratio 8:1 is also significantly different from the null expectation of 50:50 $(P=0.039)$.

\section{Euphydryas aurinia}

There was a strongly protandrous pattern of emergence (Fig. 1), with the mean day of emergence of males on day 20.8 (day 21 is 16 June) and of females on day 29.4 (24 June). The male emergence period lasted for longer ( $\mathrm{sd}$ of emergence date $=9.6$ ) than that of females ( $\mathrm{sd}$ of emergence date $=4.2$ ). The last fresh individuals newly captured were 2 males on day 43, while the last fresh females were on the two previous days (with one individual each time). The total population sizes over the entire flight period were estimated at 324 males and 204 females.

Neither days of capture for each sex, nor wing length follow a normal distribution (all four Shapiro-Wilk normality test, being highly significant $P<0.001)$. For males the size decreased from the beginning to the end of the season (Fig. 2, Spearman's $\rho=-0.206$, $\mathrm{n}=152, P=0.011$ ), while the trend for females was for increasing size with time, albeit not significantly (Spearman's $\rho=-0.205, \mathrm{n}=86, P=0.058$ ). 


\section{Discussion}

In many temperate-zone arthropods the developmental stage of all individuals in the same generation is synchronized at diapause, so that variation in timing of birth in summer has lost its influence when development re-starts in the following springtime. Furthermore, generations are generally discrete, such that adults from one generation are dead by the time the next generation of adults appears. In the absence of variation in speed of development (which does exist, Nylin and Gotthard 1998; Fischer et al. 2004), insects programmed to be larger will take longer to develop and emerge later (Zonneveld 1996). Conversely, insects programmed to emerge early may need to be small, in which case natural selection acting on timing of maturity will affect evolution of adult size. Evolution of sex-specific timing may generate sexual dimorphism in size (Singer 1982).

These genetic constraints generate the expectation of a phenotypic covariance between size and timing: early insects should be smaller, late ones larger. However, this expected relationship can be reversed by plastic responses to environmental variation (Higgins 2000) and these plastic responses may themselves be sex-specific (Fischer and Fiedler 2001b).

Why might the sexes respond differently to environmental stress? The collective works of Wiklund and Kaitala (1995) and of Leimar et al. (1994) give a relevant example. In the butterfly Pieris napi, male-donated nuptial gifts were large, so that females could potentially increase their mating frequency to compensate any reduction of fecundity, such as that conferred by small body size. These authors suggested that size should be less important to females than to males. This prediction was supported by the experimental finding that females yielded size more readily than males when larvae were fed a low quality diet. This experiment showed clearly that the sizes achieved by adult males and females can respond differently to the same environmentally-imposed variation.

Our own study began with a set of observations that both the first and the last butterflies to emerge in our study population of E.editha were almost always males. This dataset now extends to 20 years, in only one of which the latest freshly-emerged insect observed was female. The male emergence season was longer that that of females, contrary to the hypothesis of approximately equal emergence time for males and females used in Fagerström and Wiklund's (1982) model. The last males to emerge appeared when they had no opportunity to encounter virgin females. This did not mean that a late male could not mate, as approximately $10 \%$ of female E. editha mate twice (Ehrlich and Ehrlich 1978) but a late male's opportunities to mate were much reduced, as was the expected number of offspring that it could father if it did mate. The consistent appearance of late males is especially paradoxical in E. editha, because its larvae can respond to perceived adversity by repeated diapause. A male larva that found itself late could re-enter diapause and try again next year, starting from a larger initial size.

Why might females emerge over a shorter period than males? If size were more important to male E.editha than to females, as is the case in P. napi, then males that suffer environmentally-imposed time delays should be less likely than equally-delayed females to yield size in an effort to maintain

Nève \& Singer. Protandry and postandry in Euphydryas butterflies, Evol. Ecol (2008) 22:701-709, page 5 
phenology. This would provide a satisfying explanation of both the postandry that occurs in the field and the difference between the sexes in the size trend over time. The necessary environmental variation to fuel this effect is provided by patchy snowmelt. E.editha larvae diapause under snow and commence feeding almost immediately after snowmelt. Within a single site, snow patches melt at different times, creating phenological differences of 1-3 weeks among individual larvae. Delayed larvae have the option to re-enter diapause and complete development in the following year but not all of them do so. Those delayed larvae that continue development could be viewed as having two very different options. They could maintain predetermined size regardless of phenology or predetermined phenology regardless of size. Neither of these extreme cases would generate a phenotypic association between time and size. However, any intermediate response between the two extremes would do so. For example, a larva that was delayed ten days by snowmelt would have the option of emerging with only seven days' delay but reduced in size by three days' growth. If larvae in general did this, then late-emerging adults would be smaller than early ones. This is the relationship that we see between size and phenology of female E. editha. In contrast, delayed male $E$. editha evidently were not reduced in size. The male emergence period was extended relative to that of females, as both the first and last individuals to emerge were typically males.

The entire dataset from E. editha is consistent with the hypothesis that females delayed by late snowmelt traded size against time, while delayed males did not. Why should females do this? We might expect to discover some reason why size is less important to females than to males, or some reason why timing is less important to males than to females. We have observed no such phenomena. It is not likely that females can compensate for small size by mating frequently as in $P$. napi, since nuptial gifts in E. editha are very small (Boggs and Nieminen 2004). Neither is it true at this site that strong selection on timing of oviposition arises from seasonal effects on offspring mortality, since survival on the traditional host at Rabbit Meadow was identical for early, mid-season and late eggs (Boughton 1999). In sum, our current knowledge of E. editha biology merely allows us to discount some obvious possible sources of selection that would shorten the female emergence season but identifies no clear source of such selection.

In our other study species, E. aurinia, the most likely source of environmental variation is not time of breaking diapause but shortage of food for large larvae that have defoliated their hosts and must either search for new hosts or pupate at the size they have already achieved, especially as individuals of the E. aurinia's foodplant, Succisa pratensis, often grow singly on this site. Boggs and Freeman (2005) showed that a lowering of larval resources reduces adult mass, forewing length and fitness. This effect could render late individuals small by the same type of trade-off we suggested for E. editha. Like E. editha, the E.aurinia population that we studied showed a difference between the sexes in the association between adult size and time of emergence. However, this difference was in the opposite direction from that in E. editha. Late-emerging males were small, late-emerging females were not. By the argument we have developed here, we expect the sex that sacrifices size when it is delayed to have the shorter emergence period. This is true for E. editha but not for E. aurinia. At present we lack a sensible explanation for this difference. In this as in any comparison involving only two species and two sites, the question remains open as to whether the observed difference is due to site or to species difference or both (Garland and Adolph 1994).

Nève \& Singer. Protandry and postandry in Euphydryas butterflies, Evol. Ecol (2008) 22:701-709, page 6 
Any difference between E. aurinia and E. editha in the experience of environmental variation by larvae should apply equally to males and females, so it would not account for the difference between the species that we observed. Any comprehensive explanation should involve differences between the species in the relative importance of size and timing to male and female fitness. Investigation of these differences should be a fruitful avenue to understanding how genetic and environmental variation interact to generate correlations among important life-history traits in natural habitats.

\section{Acknowledgements}

Philippe Goffart, David Boughton and Chris Singer helped gather the data. We thank Philippe Lebrun and Michel Baguette (University of Louvain) and the Ministère de la Région Wallonne for support to the E. aurinia study.

\section{References}

Arnason AN, Schwarz CJ (1999) Using POPAN-5 to analyse banding data. Bird Study 46 (suppl): S157-168

Arnason AN, Schwarz CJ, Boyer G (1998) POPAN-5: A data maintenance and analysis system for markrecapture data.. Department of Computer Science, Winnipeg

Benard MF (2004) Predator-induced phenotypic plasticity in organisms with complex life histories. Ann Rev Ecol Syst 35: 651-673

Berger D, Walters R, Gotthard K (2006) What keeps insects small? - Size dependent predation on two species of butterfly larvae. Evol Ecol 20: 575-589

Boggs CL, Freeman KD (2005) Larval food limitation in butterflies: effects on adult resource allocation and fitness. Oecologia 144: 353-361

Boggs CL, Nieminen M (2004) Checkerspot Reproductive Biology. In: Ehrlich, PR, Hanski I (eds) On the Wings of Checkerspots. Oxford University Press, Oxford, pp 92-111

Boughton DA (1999) Empirical evidence for complex source-sink dynamics with alternative states in a butterfly metapopulation . Ecology 80: 2727-2739

Candolin U, Voigt HR (2003) Size-dependent selection on arrival times in sticklebacks: why small males arrive first. Evolution 57: 862-871

Ehrlich AH, Ehrlich PR (1978) Reproductive strategies in the butterflies. I. Mating frequency, plugging, and egg number. J Kansas Ent Soc 51: 666-697

Fagerström T, Wiklund C (1982) Why do males emerge before females ? Protandry as a mating strategy in male and female butterflies. Oecologia 52: 164-166

Fischer K, Fiedler K (2001a) Sexual differences in life-history traits in the butterfly Lycaena tityrus: a comparison between direct and diapause development. Ent Exp Appl 100: 325-330

Fischer K, Fiedler K (2001b) Effects of larval starvation on adult life-history traits in the butterfly species Lycaena tityrus (Lepidoptera: Lycaenidae). Ent Gen 25: 249-254

Fischer K, Zeilstra I, Hetz SK, Fiedler K (2004) Physiological costs of growing fast: does accelerated growth reduce pay-off in adult fitness? Evol Ecol 18: 343-353.

Forrest TG (1987) Insect size tactics and developmental strategies. Oecologia 73: 178-184

Garland T Jr, Adolph S C (1994) Why not to do two-species comparative studies. Physiological Zoology 67:797-828

Higgins L (2000) The interaction of season length and development time alters size at maturity Oecologia 122: $51-59$

Iwasa Y, Odendaal FJ, Murphy DD, Ehrlich PR, Launer AE (1983) Emergence patterns in male butterflies: a hypothesis and a test. Theor Pop Biol 23: 636-379

Leimar O, Karlsson B, Wiklund C (1994) Unpredictable food and sexual size dimorphism in insects. Proc R Soc London B 258: 121-125

Nylin S, Gotthard K (1998) Plasticity in life-history traits. Ann Rev Ent 43: 63-83

Nève \& Singer. Protandry and postandry in Euphydryas butterflies, Evol. Ecol (2008) 22:701-709, page 7 
R Development Core Team (2004) R: A language and environment for statistical computing. R Foundation for Statistical Computing, Vienna. Available from http://www.R-project.org (accessed January 2007)

Singer MC (1982) Sexual selection for small size in male butterflies. Am Nat 119: 440-443

Stearns SC (1992) The Evolution of Life Histories. Oxford University Press, Oxford

Taylor BW, Anderson CR, Peckarsky, BL (1998) Effects of size at metamorphosis on stone fly fecundity, longevity, and reproductive success. Oecologia 114: 494-502

Thomas CD, Singer MC, Boughton DA (1996) Catastrophic extinction of population sources in a butterfly metapopulation. Am Nat 148: 957-975

Vonesh JR, Warkentin KM (2006) Opposite shifts in size at metamorphosis in response to larval and metamorph predators. Ecology 87: 556-562

Wiklund C, Forsberg J (1991) Sexual size dimorphism in relation to female polygamy and protandry in butterflies: a comparative study of Swedish Pieridae and Satyridae. Oikos 60: 373-381

Wiklund C, Kaitala A (1995) Sexual selection for large male size in a polyandrous butterfly: the effect of body size on male versus female reproductive success in Pieris napi. Behav Ecol 6: 6-13

Zonneveld C (1996) Being big or emerging early? Polyandry and the trade-off between size and emergence time in male butterflies. Am Nat 147: 946-965 
Table 1. Forewing size of Euphydryas editha specimens, according to sex and time in 1995 and 1996.

\begin{tabular}{|c|c|c|c|c|}
\hline & $N$ & Mean & $t$ & $P$ \\
\hline \multicolumn{5}{|c|}{1995 Female wing length } \\
\hline Time 1 & 25 & $21.80 \mathrm{~mm}$ & & \\
\hline Time 2 & 49 & $20.89 \mathrm{~mm}$ & 4.40 & 0.0001 \\
\hline \multicolumn{5}{|c|}{1995 Male wing length } \\
\hline Time 1 & 27 & $18.93 \mathrm{~mm}$ & & \\
\hline Time 2 & 38 & $19.37 \mathrm{~mm}$ & -2.17 & 0.034 \\
\hline \multicolumn{5}{|c|}{1996 Female wing length } \\
\hline Time 1 & 66 & $21.69 \mathrm{~mm}$ & & \\
\hline Time 2 & 45 & $21.06 \mathrm{~mm}$ & 3.16 & 0.002 \\
\hline \multicolumn{5}{|c|}{1996 Male wing length } \\
\hline Time 1 & 67 & $19.37 \mathrm{~mm}$ & & \\
\hline Time 2 & 37 & $19.56 \mathrm{~mm}$ & -1.19 & 0.237 \\
\hline
\end{tabular}

All $t$ tests were between data from time 1 and time 2 per year and sex. 

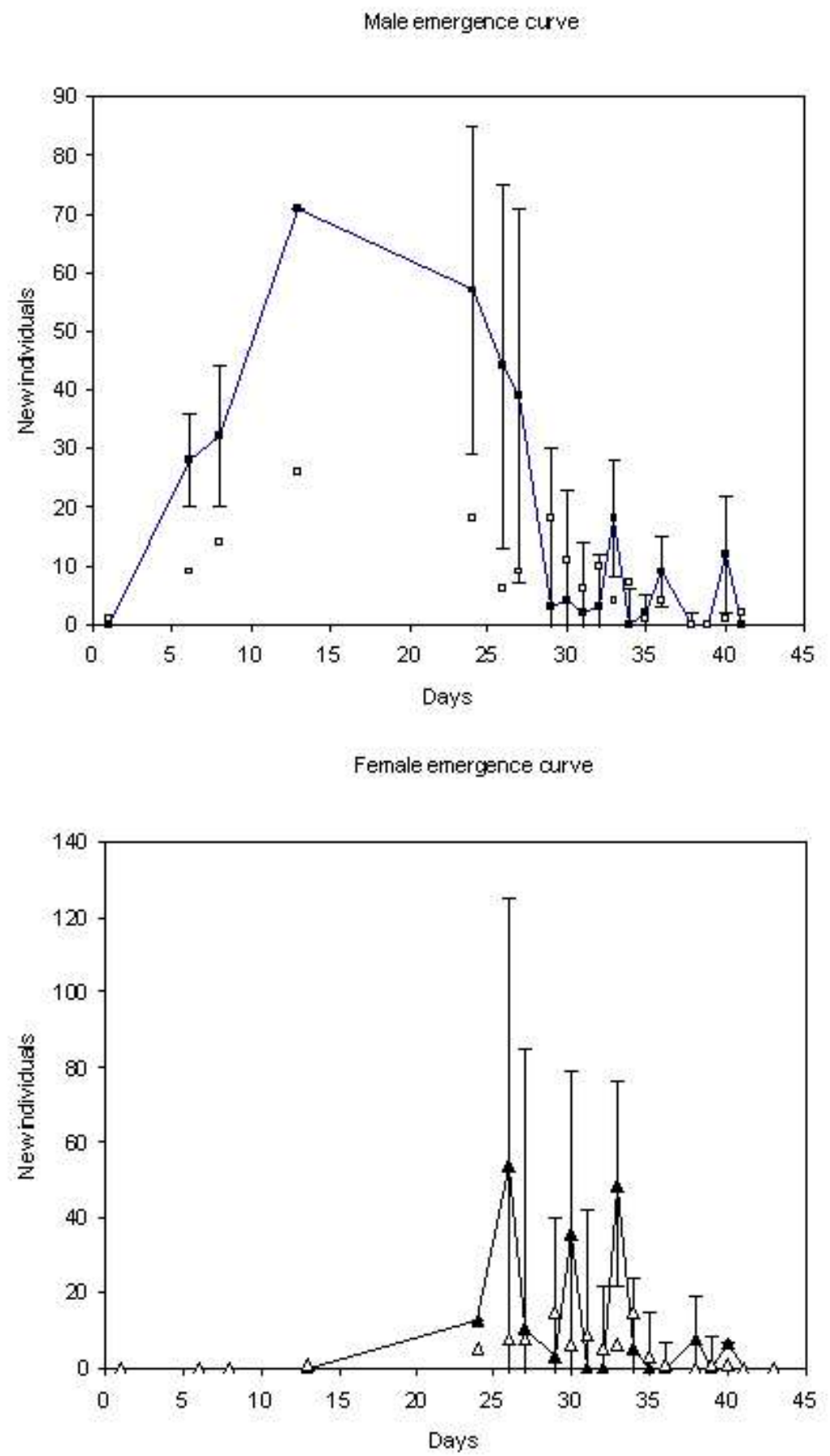

Figure 1. Emergence curves for E. aurinia at Deiffelt in 1995, as the estimates of numbers of new individuals in the population at each capture session, according to using Jolly-Seber model. Vertical bars indicate s.e. of estimates, when available. Hollow symbols indicate the numbers of freshly emerged individuals having actually been captured. Day 1 is 27 May 1995. 

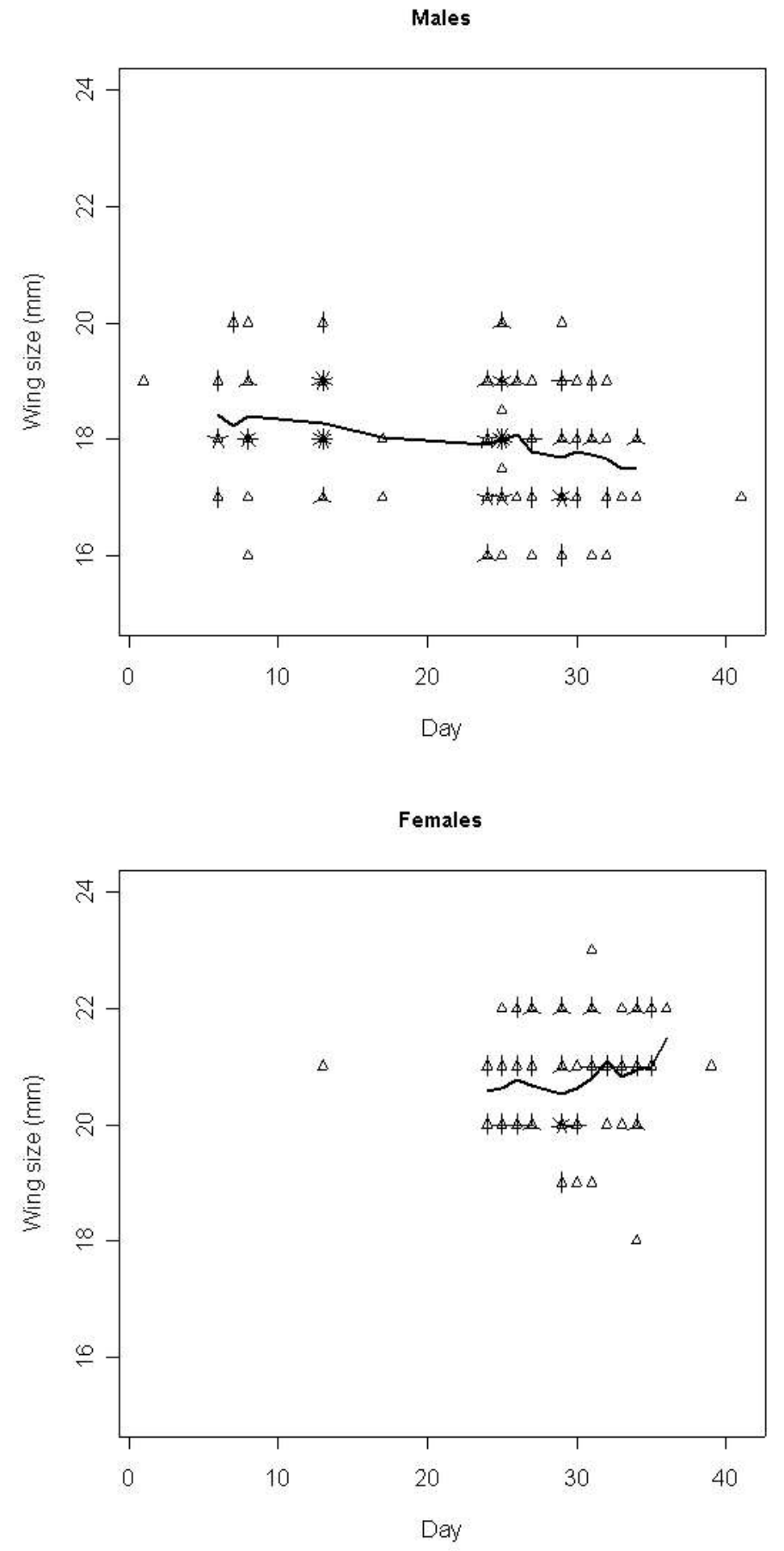

Figure 2. Forewing lengths of E. aurinia males (top) and females (bottom) captured at Deiffelt, against the days on which first captured in 1995 (Day 1 is 26 May). Only wingwear classes 1 and 2 (out of 4) are considered. Multiple points are plotted with the numbers of radius bars corresponding to the numbers of observations. Lines depict running mean wing length for individuals captured during three consecutive trapping sessions. 